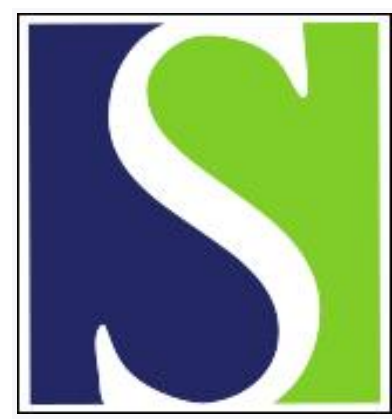

Scand J Work Environ Health 2020;46(1):60-68

https://doi.org/10.5271/sjweh.3840

Published online: 27 Jun 2019, Issue date: 01 Jan 2020

The influence of multiple occupational exposures on absence from work in pregnancy: a prospective cohort study

by Sejbaek CS, Pedersen J, Schlünssen V, Begtrup LM, Juhl M, Bonde JP, Kristensen P, Bay H, Ramlau-Hansen CH, Hougaard KS

Affiliation: National Research Centre for the Working Environment, Lersø Parkalle 105, DK-2100 Copenhagen, Denmark. css@nfa.dk

Refers to the following texts of the Journal: 2015;41(4):397-406 2015;41(4):338-346 2013;39(4):335-342 2007;33(3):233-239 1997;23(5):378-384

Key terms: absence from work; cohort study; epidemiology; exposure; job control; job demand; lifting; occupational exposure; pregnancy; pregnancy-related absence; prospective cohort study; work posture; work shift

This article in PubMed: www.ncbi.nlm.nih.gov/pubmed/31247116 


\title{
The influence of multiple occupational exposures on absence from work in pregnancy: a prospective cohort study
}

\author{
by Camilla Sandal Sejbaek, PhD, ${ }^{1}$ Jacob Pedersen, PhD, ${ }^{1}$ Vivi Schlünssen, PhD, ${ }^{1,2}$ Luise Mølenberg Begtrup, PhD, ${ }^{3}$ Mette Juhl, \\ PhD, ${ }^{4}$ Jens Peter Bonde, PhD, ${ }^{3}$ Petter Kristensen, PhD, ${ }^{5}$ Hans Bay, Cand stat, ${ }^{1}$ Cecilia Høst Ramlau-Hansen, PhD, ${ }^{6}$ Karin Sørig \\ Hougaard, $P h D^{1,7}$
}

\begin{abstract}
Sejbaek CS, Pedersen J, Schlünssen V, Begtrup LM, Juhl M, Bonde JP, Kristensen P, Bay H, Ramlau-Hansen CH, Hougaard KS. The influence of multiple occupational exposures on absence from work in pregnancy: a prospective cohort study. Scand $J$ Work Environ Health. 2020:46(1):60-68. doi:10.5271/sjweh.3840
\end{abstract}

\begin{abstract}
Objectives Many women experience absence periods from work during pregnancy. Several single risk factors for absence are identified, whereas the impact of multiple concurrent exposures has been sparsely studied. We hypothesized that the presence of multiple occupational exposures would be associated with an increased risk of absence from work during pregnancy.
\end{abstract}

\begin{abstract}
Methods We included women from the Danish National Birth Cohort (1996-2002), pregnant with one child and working $\geq 30$ hours/week at interview (mean gestational week 17 (standard deviation 4.0); $\mathrm{N}=50$ 142). Information about five occupational exposures (job demands, job control, work posture, work shift, lifting) were retrieved from the interview, each assigned values of $0 / 1$, and summed into an index (0-5). The woman's first absence from work (both regular and related to pregnancy) after the interview was available from a nationwide administrative register. We analyzed data with Cox regression using gestational age as the underlying time-variable.
\end{abstract}

Results Few women experienced none of the occupational exposures (3.6\%) and most experienced two exposures $(34.7 \%)$. Only $24.3 \%$ of the women were absent from work before gestational week 31 . The number of occupational exposures was associated with an increasing risk of absence. The adjusted hazard ratio for absence increased from 1.3 [95\% confidence interval (CI) 1.1-1.5] for one exposure to $2.9(95 \%$ CI 2.5-3.3) for four to five exposures compared to no occupational exposure.

Conclusion The higher the number of potentially adverse occupational exposures pregnant women experienced, the higher the risk for absence from work during pregnancy.

Key terms epidemiology; pregnancy-related absence; job control; job demand; lifting; work posture; work shift.

A large proportion of women experience absence from work during pregnancy. In Denmark, two thirds of all pregnant women were absent from work at some point during pregnancy, and almost one third of the pregnant women were absent for $>8$ weeks during pregnancy. Furthermore, absence from work in pregnancy seems to increase (1). In 2016, the employment rate was $72 \%$ for Danish women in the reproductive age (18-44 years)
(2), and each year around 60000 children are born in Denmark. The societal costs due to absence from work are therefore high due to payment of benefits and reduction of manpower. Absence from work is also problematic for pregnant women because work is perceived as an important part of life. Reduction of absence from work during pregnancy therefore encompasses economic as well as individual advantages. It is therefore important

1 National Research Centre for the Working Environment, Copenhagen, Denmark.

2 Department of Public Health - Institute of Environment, Occupation and Health, Aarhus University, Aarhus, Denmark.

3 Department of Occupational and Environmental Medicine, Bispebjerg University Hospital, Copenhagen, Denmark.

4 Faculty of Health, Department of Midwifery and Therapeutic Sciences, University College Copenhagen, Copenhagen, Denmark.

5 Department of Occupational Medicine and Epidemiology, National Institute of Occupational Health, Oslo, Norway.

6 Department of Public Health - Section for Epidemiology, Aarhus University, Aarhus, Denmark.

7 Department of Public Health, Section of Occupational and Environmental Health, University of Copenhagen, Copenhagen, Denmark.

Correspondence to: Camilla Sandal Sejbaek, PhD, National Research Centre for the Working Environment, Lersø Parkalle 105, DK-2100 Copenhagen, Denmark. [E-mail: css@nfa.dk]. 
to study how occupational exposures may be associated with absence from work during pregnancy to enable formulation of efficient preventive measures.

A number of occupational factors have been described as risk factors for absence from work during pregnancy. Previous studies have investigated occupational exposures such as job strain [defined by the combination of job demands and job control (3)], work posture, lifting, and work shift. These were each associated with the first episode of absence during gestational week (GW) 10-29 of pregnancy in a previous Danish study (4); while another study found similar exposures to be associated to absence for $>10 \%$ of the scheduled work time during pregnancy among hospital employees (5). The relationship between occupational exposures and absence from work during pregnancy has mostly been assessed for individual factors, one at a time, rather than for combinations of exposures. However, one crosssectional study investigated an index of occupational exposures and showed that, with an increasing number of exposures, the risk of self-reported sickness absence during pregnancy increased (6). Findings described in a Danish report indicated that pregnant women concurrently exposed to several occupational exposures had more absences from work than pregnant women with fewer or no exposures at work (7). This study was crosssectional, sickness absence was self-reported, and details of the analyses were not available. Hence, in research of associations between occupational exposures and absence from work during pregnancy, there is a need to use prospective study designs and register rather than self-reported data on the outcome.

We hypothesized that exposure to multiple concurrent occupational exposures would increase the risk of absence from work. We constructed an index of several occupational exposures (4) with the hypothesis that exposures, which have been indicated to relate to absence from work during pregnancy, will also increase the risk of absence when they are present concurrently and that the risk will increase for additional exposures, ie, the higher the number of exposures the higher the risk of absence.

\section{Methods}

\section{Study population}

We used data from the Danish National Birth Cohort (DNBC) with 100418 pregnancies (1996-2002) (8). During the first antenatal visit, the general practitioner invited the pregnant women to participate in the cohort if they planned to complete the pregnancy, lived in Denmark, and could carry out a comprehensive telephone interview in Danish. For more details, see elsewhere (8).

We included women if they (i) completed DNBC's first pregnancy interview between the first day in $\mathrm{GW}$ 11 and the last day in GW 30 [mean 16.7 (SD 4.0) GW], (ii) were pregnant with their first singleton pregnancy registered in the DNBC, (iii) worked $\geq 30$ hours per week, and (iv) had full information on all exposures of interest, covariables and outcome (figure 1, N=50 142).

The DNBC and the Danish Data Protection Agency permitted use and storage of data at Statistics Denmark where the available data were fully anonymized. According to the Danish legislation, approval from the Ethical Committee was not needed.

\section{Occupational exposures}

An index variable constructed, as described by Miranda and colleagues (9), was generated from the five selected occupational exposures: work posture, work shift, lifting, job demands, and job control (table 1). These factors were included in the analyses as they had previously been found to be associated with absence from work during pregnancy, albeit job demands and job control was associated to absence from work as the combined exposure job strain (4). Lifting was constructed from four questions, while the rest of the exposures were based on one question each (table 1). Each heavy and medium lift were assigned values of 22.5 and $15 \mathrm{~kg} / \mathrm{lift}$, respectively, and the cumulative burden of lifting was calculated (10). The scoring of lifting, work posture and work shift ( 0 or 1 point; table 1$)$ was based on the findings in Hansen et al (4). Job demands and job control were included as separate measures, dichotomized and scored ( 0 or 1 point; table 1 ) based on Larsen et al (11) and Juhl et al (12). These two questions were dichotomized in order to obtain as much contrast as possible. For the index variable, the points were summarized across the five occupational exposures for each woman. The final index variable ranged from $0-5$, where 4 and 5 were combined into one category due to an assumption that few women would experience a high amount of occupational exposures.

\section{Outcome}

Information on doctor-certified absence from work was obtained from the Danish Register for Evaluation of Marginalization (DREAM). This register contains data for all types of social payments with unique codes for each benefit, eg, sickness and maternity benefit, educational funds, and retirement pension. The data has a hierarchical structure and is assessed on a weekly basis with one code registered in DREAM per week. Absence from work during pregnancy was registered as either regular or pregnancy-related. Regular sickness absence 


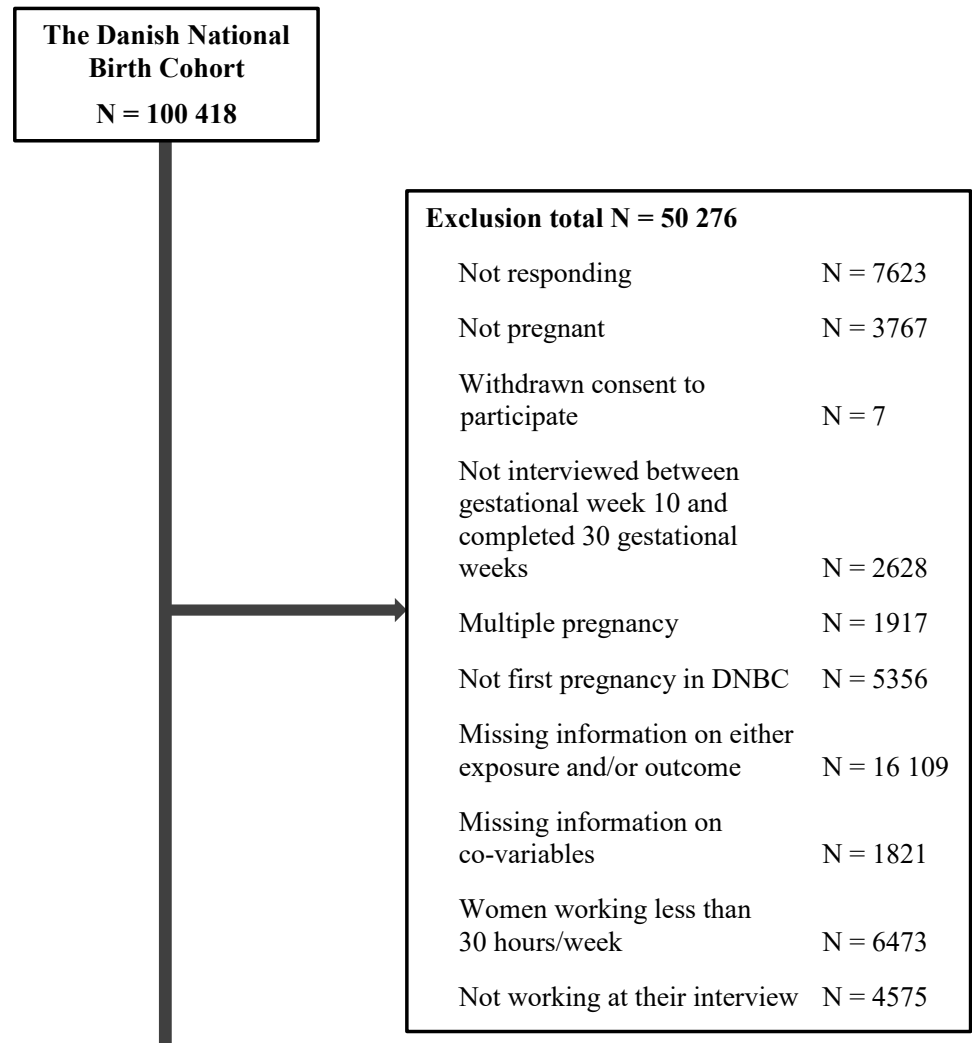

Figure 1. Flowchart of the study population, the Danish National Birth Cohort (DNBC), 1996-2002.

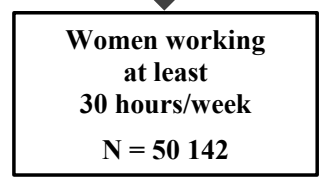

was registered if the women were absent from work for $\geq 15$ days and subsequently backdated to day 1 . Pregnancy-related absence from work relates to absence due to pregnancy factors, eg, pelvic pain or harmful working condition(s) for mother or child and was registered from the first day of absence. In order for the absence period, no matter the type, to be entered into DREAM it had to be doctor-certified. For the two types of absence, the employers were reimbursed for the sickness benefit from day 15 and 1, respectively. Pregnancy-related absence constituted $88.0 \%$ and regular sickness absence $12.0 \%$ of the total absences from work during pregnancy. These two were in the statistical analyses combined into a single outcome (yes/no) and the term "absence from work" is used for the outcome measure in the following.

\section{Potential confounders}

We investigated the previous literature and incorporated the identified potential confounders in a directed acyclic graph (DAG). This served as partial basis for selection of confounders together with the availability of information in the interview and the DREAM register. We included sickness absence during the year prior to pregnancy and during early pregnancy (until the first interview), which were combined into the variable previous sickness absence. The other confounders included were maternal age at conception, parity, fertility treatment, socio-economic status (SES), pre-pregnancy body mass index, during pregnancy smoking and leisure time exercise. SES was based on self-reported job titles converted into the Danish International Standard Classification of Occupations (DISCO-88). The confounders are presented in table 2 .

\section{Statistical analysis}

In the analyses, we investigated the association between the index variable and absence from work. We analyzed data in Cox proportional hazard regression models with adjustment for covariates with gestational age (days) as the underlying time variable. Calculation of gestational age was based on the self-reported first day of the last menstrual period from the interview. Entry time was 
Table 1. Occupational exposures included in the index variable. The questions from the Danish National Birth Cohort, response keys and allocation of points for each exposure.

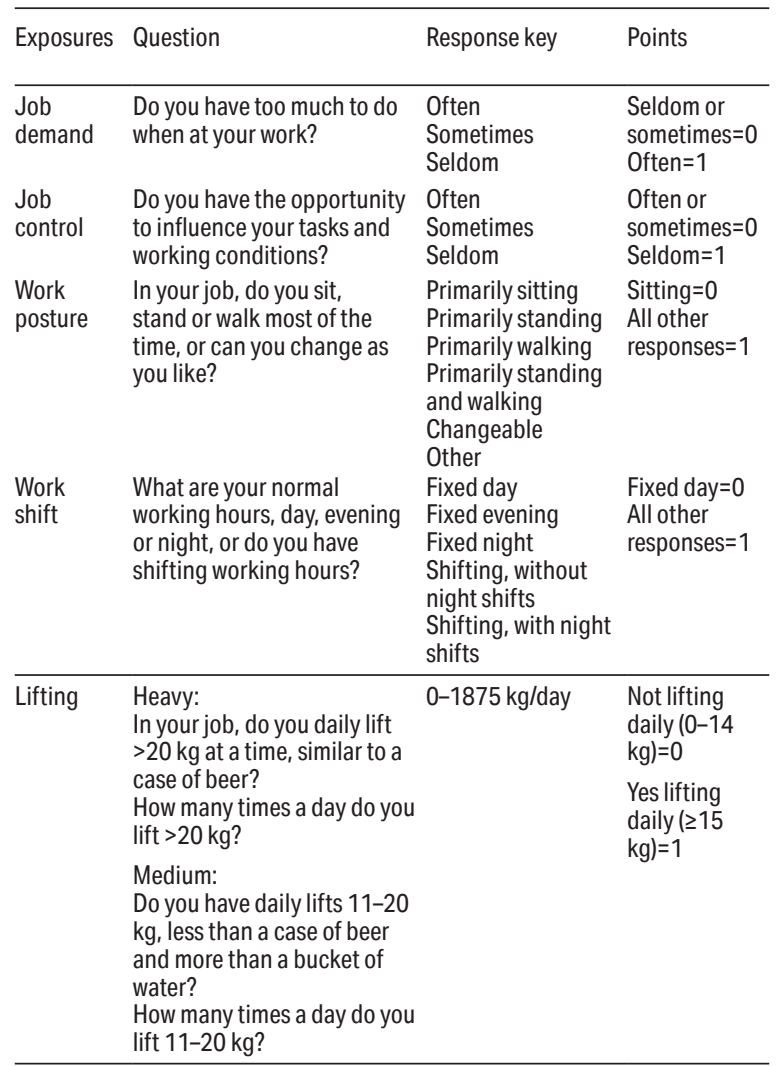

the date of the interview, and end time was the date of receiving the first episode of absence from work after the interview. Observations were censored if the women terminated pregnancy, gave birth (stillbirth or preterm birth), emigrated, went on leave other than maternity leave, received other social benefits, or the end of the study period was reached at 30 completed GW, whichever came first.

All variables were tested relative to the proportional hazard assumption by investigating the cumulative proportional hazards and reclassified when needed (see footnotes to table 2).

The results are presented as hazard ratios (HR) with $95 \%$ confidence intervals (CI) from the crude and two adjusted models; one model including all potential confounders except SES, and one model also including SES. A third model was included because inclusion of SES might result in over-adjustment.

Previous sickness absence could indicate an inherent propensity for later sickness absence (13). In the subgroup analyses, we therefore conducted the analyses with the women stratified into four groups based on their absence from work prior to pregnancy $(0,1-2,3-5$, and $\geq 6$ weeks absence) and on their absence from work both prior to and during early pregnancy (see categorization in table 2). As a sensitivity analysis, we investigated the index variable with six categories instead of five in relation to absence from work.

The statistical analyses were conducted in SAS 9.4 (SAS Institute Inc, Cary, NC, USA).

\section{Results}

In this study, $24.3 \%$ of the women had their first spell of absence from work before GW 31, on average at GW 24.0 (SD 4.7). About $80 \%$ of the women experienced between 1-3 occupational exposures, while $<4 \%$ experienced 0 exposure at work of interest for this study. Women in the youngest age group or with lower educational level, more children, more smoking, or higher BMI experienced more exposures at work. Previous sickness absence was also associated with more exposures at work. Women who had received fertility treatment experienced less exposures compared to women without fertility treatment (table 2).

The women were on average followed for 11.6 weeks; women registered with absence from work were followed for 7.6 weeks (mean), while women with no absence from work were followed for 12.9 weeks (mean). Both the crude and adjusted analyses showed that with an increasing number of occupational exposures the risk of absence from work increased (figure 2), albeit adjustment attenuated the findings both from model 1 to 2 and from model 2 to 3 . In the fully adjusted analysis, the HR increased from $1.25(95 \% \mathrm{CI}$ $1.08-1.45)$ for one occupational exposure to $2.87(95 \%$ CI 2.49-3.30) for 4-5 compared with 0 occupational exposures (figure 2).

In a sensitivity analysis, we investigated the index as a 6-category variable, ie, without combining 4 and 5 occupational exposures. Being exposed to 4 occupational exposures resulted in the fully adjusted analysis in a HR of 2.77 (95\% CI 2.40-3.19) for absence from work, exposure to 5 occupational exposures gave a HR of 3.23 (95\% CI 2.77-3.77) for absence from work. Hence, the risk of absence from work further increased when the number of occupational exposures increased from 4 to 5 .

We conducted subgroup analyses to test for effect modification by previous sickness absence in two different analyses. First, a test of effect modification by sickness absence prior to pregnancy $(0,1-2,3-5$ and $\geq 6$ weeks) was investigated for the index variable. In each of the subgroups in this variable, we found a pattern with increasing number of occupational exposures the risk of absence from work also increased. For women with no sickness absence prior to pregnancy, the risk 
Table 2. Characteristics of the pregnant women by the index variable.

\begin{tabular}{|c|c|c|c|c|c|c|c|c|c|c|}
\hline \multirow[t]{3}{*}{ Characteristics } & \multicolumn{10}{|c|}{ Index variable } \\
\hline & \multicolumn{2}{|c|}{0} & \multicolumn{2}{|c|}{1} & \multicolumn{2}{|c|}{2} & \multicolumn{2}{|c|}{3} & \multicolumn{2}{|c|}{$4-5$} \\
\hline & $\mathrm{N}$ & $\%$ & $\mathrm{~N}$ & $\%$ & $\mathrm{~N}$ & $\%$ & $\mathrm{~N}$ & $\%$ & $\mathrm{~N}$ & $\%$ \\
\hline Total (N = 50 142) & 1780 & 3.6 & 9763 & 19.5 & 17410 & 34.7 & 12967 & 25.9 & 8222 & 16.4 \\
\hline \multicolumn{11}{|l|}{ Maternal age at birth (years) } \\
\hline$<25$ & 118 & 2.3 & 754 & 15.0 & 1532 & 30.4 & 1489 & 29.6 & 1146 & 22.7 \\
\hline $25-29$ & 669 & 3.1 & 3985 & 18.7 & 7300 & 34.3 & 5588 & 26.2 & 3756 & 17.6 \\
\hline $30-34$ & 777 & 4.3 & 3809 & 21.1 & 6458 & 35.8 & 4500 & 24.9 & 2509 & 13.9 \\
\hline$\geq 35$ & 216 & 3.8 & 1215 & 21.1 & 2120 & 36.9 & 1390 & 24.2 & 811 & 14.1 \\
\hline \multicolumn{11}{|c|}{ Gestational age (weeks) at interview } \\
\hline$<17$ & 924 & 3.5 & 4871 & 18.6 & 8829 & 33.8 & 6763 & 25.9 & 4743 & 18.2 \\
\hline $17-30$ & 856 & 3.6 & 4892 & 20.4 & 8581 & 35.7 & 6204 & 25.8 & 3479 & 14.5 \\
\hline \multicolumn{11}{|l|}{ Socioeconomic status } \\
\hline High education & 342 & 5.6 & 1808 & 29.5 & 2402 & 39.2 & 1079 & 17.6 & 500 & 8.2 \\
\hline Medium education & 415 & 2.4 & 2774 & 16.3 & 5682 & 33.3 & 4630 & 27.1 & 3532 & 20.9 \\
\hline Skilled work & 701 & 6.0 & 3034 & 25.9 & 4838 & 41.2 & 2592 & 22.1 & 573 & 4.9 \\
\hline Unskilled work & 213 & 1.7 & 1582 & 12.7 & 3602 & 28.8 & 3937 & 31.5 & 3158 & 25.3 \\
\hline Student & 109 & 4.0 & 565 & 20.8 & 886 & 32.6 & 729 & 26.8 & 429 & 15.8 \\
\hline \multicolumn{11}{|l|}{ Previous sickness absence } \\
\hline No previous sickness absence & 1559 & 3.9 & 8230 & 20.8 & 14132 & 35.7 & 9764 & 24.7 & 5920 & 15.0 \\
\hline Sickness before pregnancy & 131 & 2.3 & 833 & 14.6 & 1778 & 31.3 & 1691 & 29.7 & 1256 & 22.1 \\
\hline Absence in early pregnancy & 58 & 2.0 & 390 & 13.5 & 877 & 30.2 & 901 & 31.1 & 674 & 23.2 \\
\hline $\begin{array}{l}\text { Sickness absence before and } \\
\text { during early pregnancy }\end{array}$ & 32 & 1.6 & 310 & 15.9 & 623 & 32.0 & 611 & 31.4 & 372 & 19.1 \\
\hline \multicolumn{11}{|l|}{ Parity } \\
\hline 0 & 950 & 3.6 & 5318 & 20.1 & 9216 & 34.9 & 6681 & 25.3 & 4261 & 16.1 \\
\hline 1 & 632 & 3.7 & 3316 & 19.5 & 5981 & 35.2 & 4419 & 26.0 & 2651 & 15.6 \\
\hline$\geq 2$ & 198 & 3.0 & 1129 & 16.8 & 2213 & 33.0 & 1867 & 27.8 & 1310 & 19.5 \\
\hline \multicolumn{11}{|l|}{ Smoking } \\
\hline No & 1473 & 3.9 & 7879 & 20.7 & 13556 & 35.6 & 9529 & 25.0 & 5696 & 14.9 \\
\hline Less than daily & 156 & 2.9 & 917 & 16.8 & 1829 & 33.6 & 1511 & 27.7 & 1039 & 19.1 \\
\hline Daily & 151 & 2.3 & 967 & 14.8 & 2025 & 30.9 & 1927 & 29.4 & 1487 & 22.7 \\
\hline \multicolumn{11}{|l|}{ Fertility treatment } \\
\hline No & 1640 & 3.5 & 9112 & 19.4 & 16292 & 34.6 & 12210 & 26.0 & 7801 & 16.6 \\
\hline Yes & 140 & 4.5 & 651 & 21.1 & 1118 & 36.2 & 757 & 24.5 & 421 & 13.6 \\
\hline \multicolumn{11}{|l|}{ Leisure-time physical exercise a } \\
\hline No & 1074 & 3.5 & 5867 & 19.1 & 10571 & 34.5 & 8004 & 26.1 & 5159 & 16.8 \\
\hline Yes & 706 & 3.6 & 3896 & 20.0 & 6839 & 34.1 & 4963 & 25.5 & 3063 & 15.7 \\
\hline \multicolumn{11}{|l|}{ Body mass index $\left(\mathrm{kg} / \mathrm{m}^{2}\right)^{\mathrm{b}}$} \\
\hline $15-24.9$ & 1382 & 3.8 & 7379 & 20.0 & 12937 & 35.1 & 9335 & 25.3 & 5845 & 15.9 \\
\hline $25-29.9$ & 293 & 3.1 & 1755 & 18.3 & 3304 & 34.5 & 2586 & 27.0 & 1644 & 17.2 \\
\hline $30-50$ & 105 & 2.9 & 629 & 17.1 & 1169 & 31.8 & 1046 & 28.4 & 733 & 19.9 \\
\hline
\end{tabular}

a Leisure-time physical exercise was recategorized into two categories in order to obtain the proportional hazard assumption.

${ }^{\mathrm{b}}$ Body mass index was recategorized into three categories in order to obtain the proportional hazard assumption.

of absence from work increased compared to the main analysis, ie, for $4-5$ occupational exposures, the fully adjusted HR was 3.26 (95\% CI 2.79-3.81) compared to HR 2.87 (95\% CI 2.49-3.30) in the main analysis. In the test including sickness absence prior to and during early pregnancy (no, before, early, and both before and during early pregnancy), we saw a similar pattern, except for the group of women absent from work both before and during pregnancy, where we found no association.

\section{Discussion}

Approximately $25 \%$ of the pregnant women in the study had $\geq 1$ spell of absence from work during the followup until the end of GW 30. We found an increasing risk of absence with an increasing number of occupational exposures when analyzed by use of an index variable including exposures that were earlier shown to be associated with the risk of absence (4). The results supported our hypothesis that more exposures at work led to a higher risk of absence from work.

Our findings were in line with two previous studies; a cross-sectional study showed a dose-response relationship between an cumulated index of occupational exposures and absence from work (6). However, information about both exposures and absence was collected after the women gave birth. A previous Danish report (7) also found that pregnant women exposed to several occupational exposures had an increased risk of absence from work. Our study on the other hand is, as far as we know, the first prospective study to use register information for the outcome investigating the association between combinations of occupational exposures.

Each variable included in the index was dichoto- 


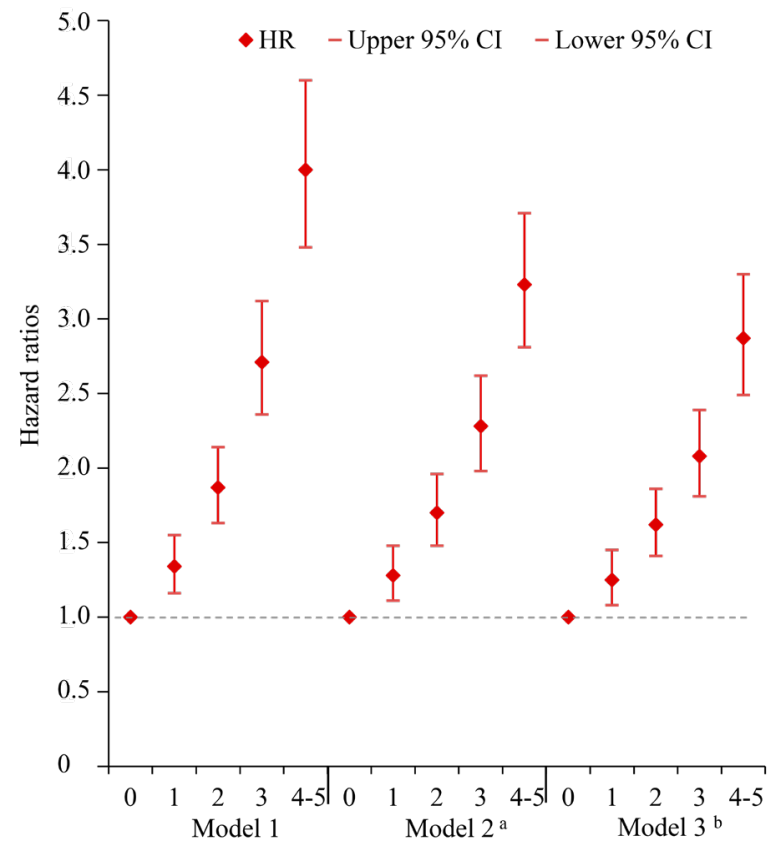

Index variable - number of occupational exposures

\begin{tabular}{|c|c|c|c|}
\hline $\begin{array}{l}\text { Index variables: } \\
\text { occupational exposures }\end{array}$ & $\mathrm{N}$ & Event & $\begin{array}{c}\text { Event/N } \\
(\%)\end{array}$ \\
\hline 0 & 1780 & 212 & 11.9 \\
\hline 1 & 9763 & 1493 & 15.3 \\
\hline 2 & 17410 & 3595 & 20.6 \\
\hline 3 & 12967 & 3687 & 28.4 \\
\hline $4-5$ & 8222 & 3218 & 39.1 \\
\hline $\begin{array}{l}\text { Index variables: } \\
\text { occupational exposures }\end{array}$ & $\mathrm{HR}$ & \multicolumn{2}{|c|}{$95 \% \mathrm{Cl}$} \\
\hline \multicolumn{4}{|l|}{ Model 1} \\
\hline 0 & 1.00 & \multicolumn{2}{|c|}{ - } \\
\hline 1 & 1.34 & \multicolumn{2}{|c|}{$1.16-1.55$} \\
\hline 2 & 1.87 & \multicolumn{2}{|c|}{$1.63-2.14$} \\
\hline 3 & 2.71 & \multicolumn{2}{|c|}{$2.36-3.12$} \\
\hline $4-5$ & 4.00 & \multicolumn{2}{|c|}{$3.48-4.60$} \\
\hline \multicolumn{4}{|l|}{ Model 2a } \\
\hline 0 & 1.00 & \multicolumn{2}{|c|}{ - } \\
\hline 1 & 1.28 & \multicolumn{2}{|c|}{$1.11-1.48$} \\
\hline 2 & 1.70 & \multicolumn{2}{|c|}{$1.48-1.96$} \\
\hline 3 & 2.28 & \multicolumn{2}{|c|}{$1.98-2.62$} \\
\hline $4-5$ & 3.23 & \multicolumn{2}{|c|}{$2.81-3.71$} \\
\hline \multicolumn{4}{|l|}{ Model $2^{\mathrm{b}}$} \\
\hline 0 & 1.00 & \multicolumn{2}{|c|}{-} \\
\hline 1 & 1.25 & \multicolumn{2}{|c|}{$1.08-1.45$} \\
\hline 2 & 1.62 & \multicolumn{2}{|c|}{$1.41-1.86$} \\
\hline 3 & 2.08 & \multicolumn{2}{|c|}{$1.81-2.39$} \\
\hline $4-5$ & 2.87 & \multicolumn{2}{|c|}{$2.49-3.30$} \\
\hline
\end{tabular}

Figure 2. Hazard ratio (HR) and 95\% confidence interval (Cl) according to the index variable comprised of five occupational exposures for absence from work.

${ }^{a}$ Adjusted for previous sickness absence, age at conception, parity, fertility treatment, smoking, leisure-time exercise, body mass index.

${ }^{\mathrm{b}}$ Same $\mathrm{as}^{\mathrm{a}}+$ socioeconomic status. mized into yes/no and job demands and control was included as separate exposures and not as job strain (3). Albeit the index variable does not distinguish between the included occupational exposures, the results yield information on the consequences of concomitant multiple occupational exposures for absence.

We had decided, a priori, to collapse exposure to four and five occupational exposures into one category as we did not think that many would experience all five at the same time, but subsequently performed the analyses with four and five occupational exposures as separate groups. Both the main and the sensitivity analysis showed a clear dose-response relationship between the index variable and absence from work with the highest risk of absence in the group experiencing five occupational exposures.

One point for discussion is whether the absence we investigate is related to work or pregnancy. The employers were reimbursed for the pregnancy-related absence from day 1 but first from day 15 for general sickness absence. The employer would therefore have had an economical incentive to report absence as pregnancy-related which might explain that regular sickness absence constituted only $12.0 \%$ of the total number of absences from work. The lack of information on the reason(s) for the absence from work in DREAM precluded distinction between regular and pregnancy-related absence. Unfortunately, the data did not provide the possibility to investigate this issue further.

In this study, SES was based on the women's selfreported job titles. SES would be expected to be highly correlated to the investigated occupational exposures; perhaps mainly the physical exposures as the types of jobs held by skilled and un-skilled workers would be depicted by more physically straining work $(14,15)$. In the analyses, we adjusted for SES only in the final statistical models to avoid potential over-adjustment. Sickness absence generally increases with lower SES, in pregnant as well as non-pregnant populations (1, 16-18). An explanation of the influence of SES could be the presence of differential exposure and vulnerability. Differential exposure refers to the number of differential exposures either as type, duration, or amount that varies between the social positions and thereby the health risks (19). The lower the SES, the higher the risk of being exposed to risk factors and not only in the professional life. This might entail that the impact of a single (occupational) exposure could be stronger in groups of lower compared to groups of higher SES, ie, differential vulnerability (19). However, adjustment for SES only discretely attenuated estimates. Another explanation could also be different attitudes towards working during pregnancy and personality, which we could not control for due to lack of data.

The women from the DNBC were probably healthier 
than the general population. Previously, Jacobsen and colleagues (20) showed that women with low socioeconomic resources were underrepresented in this cohort, and furthermore, we only included women with $\geq 30$ weekly work hours and excluded women receiving sickness benefit due to special circumstances. Less than $25 \%$ of the pregnant women were absent from work. Other studies or reports found levels of absence from work in pregnancy of 43-68\%, irrespective of weekly working hours and time of absence from work in pregnancy (1, $4,21,22)$. We, on the other hand, investigated the risk of absence from work in a rather healthy cohort and showed that even here the risk of absence increases with an increasing number of occupational exposures.

The study was conducted within the DNBC, which was established between 1996 and 2002, ie, around 20 years ago. The recommendations issued by the Danish Work Environment Authorities on working conditions for pregnant women have not changed much since 2002 (23-25). Only one major change regarding lifting has been introduced over the years, as the recommendation has been eased since 2009: the maximum lifting restriction of $1000 \mathrm{~kg}$ per day has been removed (23-26). Psychosocial working conditions were first mentioned in 2002 , solely to be considered together in combinations with other factors such as lifting (24).

The findings from the subgroup analyses partly confirmed our main findings for women with no prior absence due to sickness. However, for women with previous sickness absence, the subgroup analyses did not show the same results as the main findings. This might be due to the small numbers, or perhaps women with previous sickness absence become absent during pregnancy earlier than pregnant women without previous sickness absence, and therefore no association was shown in these subgroups.

Our study suggests that absence from work among pregnant women may potentially be reduced by lowering the number of occupational exposures. Studies on absence from work show that women are most often absent due to general pregnancy-related discomfort, which can be exacerbated when doing strenuous work. Hence, job adjustment can help pregnant women to continue working. This is indicated by previous studies, showing that absence can be reduced if job adjustment is considered relevant and implemented $(27,28)$. At Akershus University Hospital in Oslo, a new approach was implemented where all newly pregnant employees were offered an interview with their leader and a midwife early in pregnancy to explore the need for and implement job adjustment. The hospital subsequently experienced a large reduction in absence among their pregnant employees (29).

A priori, we wished to investigate the combined effect of two specific occupational exposures - lifting and job strain - in relation to absence from work. However, due to power issues when including a 16-category variable of combined lifting (10) and job strain (3) and the two main effects (lifting and job strain) in the same analyses, we did not include these (data not shown).

The major strengths of this study include the large cohort with prospective data collection combined with national register data on the outcome. In addition, we only included women working $\geq 30$ hours/week because fewer weekly work hours could increase recuperation from work-related strain and thereby reduce the need for reduction of work by absence. This is supported by findings of reduced absence from work among pregnant women working $\leq 30$ hours/week (22). In contrast, a previous study on absence during pregnancy based on the DNBC showed that pregnant women working $<37$ hours/week had an increased risk of absence, while women working $>37$ hours/week had a decreased the risk of absence, both compared to women working 37 hours/week (4). However, women working $>37$ hours/ week might be a selected group and more robust, hence, their risk of absence during pregnancy is lower.

One limitation relates to the choice of the five occupational exposures included in the index. Other exposures such as social relationships, including quality of leadership and social support, or workplace violence, including physical violence and bullying, could have been included. However, work posture, work shift, and lifting, were previously investigated in relation to absence in pregnancy in DNBC (4). Job strain was also previously studied for this outcome, albeit not with job demands and job control as separate measures (4). Of note, we have not taken the potential correlation of the variables into account. However, the correlations of the variables were tested after the index variable was created. The results showed that only lifting and work posture were moderately to strongly correlated, while the other variables were less correlated. The results for each increment in the index may therefore not be completely independent of each other, but the normal distribution of the index variable as a variable ranging from 0 to 5 is reassuring. The questions used to generate the index were not validated, which could have led to bias. The most likely scenario would be non-differential misclassification and potential bias toward the null.

Notwithstanding these limitations, a cautious recommendation based on the presented findings would be to raise awareness of the number of occupational exposures that pregnant women experience. The novelty with the present study is that the number of exposures could possibly be a way to assess the risk of absence in pregnancy. This knowledge may be used to guide the employers on how to reduce absence from work among pregnant employees through an exposure reduction when several concomitant exposures are present at a time. This recom- 
mendation aligns well with the guidelines from the Danish Working Environment Authority (23) that the work conditions of pregnant women ought to be assessed as a whole in cases with exposure to high physical strain. Furthermore, initiatives of job adjustment addressing the straining occupational exposure might be one way to decrease absence from work in this group of workers.

\section{Concluding remarks}

We found the number of occupational exposures including job demands, job control, work posture, work shift and lifting, associated with an increased risk of absence from work during pregnancy. It may be useful to develop an index of work exposures with suggested adverse effects on absence from work during pregnancy. Thereby, it would be possible to identify pregnant women needing exposure reduction at work or to identify workplaces with a general need for preventive interventions to reduce absence among pregnant employees. Future studies should investigate job adjustment by addressing the number, type, and quality of occupational exposures among pregnant women that might reduce absence from work during pregnancy to reduce discomfort, absence, and societal and personal costs.

\section{Acknowledgments}

The Danish National Research Foundation established the Danish Epidemiology Science Centre that initiated and created the DNBC. The cohort is furthermore funded by major grant from this foundation. Additional support for the DNBC is obtained from the Pharmacy Foundation, the Egmont Foundation, the March of Dimes Birth Defects Foundation, the Augustinus Foundation and the Health Foundation. The present study was supported by grants from the Danish Work Environment Research Foundation (grant 20150018124/3).

The authors declare no conflicts of interest.

\section{References}

1. Danish Ministry of Employment. Analyse af graviditetsbetinget fravær [Analysis of pregnancy-related absence]. Copenhagen (DK): Danish Ministry of Employment, 2010 May.

2. Statistics Denmark. Erhvervs- og beskæftigelsesfrekvenser (ultimo november) efter område, herkomst, alder (16-64 år), køn og frekvens (2008-2016) [Profession- and employment frequences (ultimo November) by area, ancestry, age (16-64 years), sex and frequence (2008-2016)]. 2018. Available from http://www.statistikbanken.dk/statbank5a/default. asp? $\mathrm{w}=1680$.

3. Karasek RA. Job Demands, Job decision latitude and mental strain: Implications for job redesign. Adm Sci Q 1979;24:285-308. https://doi.org/10.2307/2392498.

4. Hansen ML, Thulstrup AM, Juhl M, Kristensen JK, RamlauHansen $\mathrm{CH}$. Occupational exposures and sick leave during pregnancy: results from a Danish cohort study. Scand J Work Environ Health 2015 Jul;41(4):397-406. https://doi. org/10.5271/sjweh.3507.

5. Kaerlev L, Jacobsen LB, Olsen J, Bonde JP. Long-term sick leave and its risk factors during pregnancy among Danish hospital employees. Scand J Public Health 2004;32(2):1117. https://doi.org/10.1080/14034940310017517.

6. Henrotin JB, Vaissière M, Etaix M, Dziurla M, Malard S, Lafon D. Exposure to occupational hazards for pregnancy and sick leave in pregnant workers: a cross-sectional study. Ann Occup Environ Med 2017 May;29:12. https://doi. org/10.1186/s40557-017-0170-3.

7. Bach H, Henriksen A. Gravides sygefravær [Sickness absence among pregnant]. Copenhagen: SFI - The Danish National Centre for Social Reserach, 2010.

8. Olsen J, Melbye M, Olsen SF, Sørensen TI, Aaby P, Andersen AM et al. The Danish National Birth Cohort--its background, structure and aim. Scand J Public Health 2001 Dec;29(4):300-7. https://doi.org/10.1177/14034948010290 040201 .

9. Miranda H, Gore RJ, Boyer J, Nobrega S, Punnett L. Health behaviors and overweight in nursing home employees: contribution of workplace stressors and implications for worksite health promotion. Sci World J 2015;2015:915359. https://doi.org/10.1155/2015/915359.

10. Juhl M, Strandberg-Larsen K, Larsen PS, Andersen PK, Svendsen SW, Bonde JP et al. Occupational lifting during pregnancy and risk of fetal death in a large national cohort study. Scand J Work Environ Health 2013 Jul;39(4):335-42. https://doi.org/10.5271/sjweh.3335.

11. Larsen AD, Hannerz H, Juhl M, Obel C, Thulstrup AM, Bonde JP et al. Psychosocial job strain and risk of adverse birth outcomes: a study within the Danish national birth cohort. Occup Environ Med 2013 Dec;70(12):845-51. https://doi.org/10.1136/oemed-2013-101453.

12. Juhl M, Andersen PK, Olsen J, Andersen AM. Psychosocial and physical work environment, and risk of pelvic pain in pregnancy. A study within the Danish national birth cohort. J Epidemiol Community Health 2005 Jul;59(7):580-5. https:// doi.org/10.1136/jech.2004.029520.

13. Christensen KB, Andersen PK, Smith-Hansen L, Nielsen ML, Kristensen TS. Analyzing sickness absence with statistical models for survival data. Scand J Work Environ Health 2007 Jun;33(3):233-9. https://doi.org/10.5271/ sjweh.1132.

14. Schrijvers CT, van de Mheen HD, Stronks K, Mackenbach JP. Socioeconomic inequalities in health in the working population: the contribution of working conditions. Int $\mathrm{J}$ Epidemiol 1998 Dec;27(6):1011-8. https://doi.org/10.1093/ ije/27.6.1011.

15. Sejbaek CS, Bay H, Larsen AD, Kristensen P, Schlünssen 
$\mathrm{V}$, Andersen AN et al. Combined exposure to lifting and psychosocial strain at work and adverse pregnancy outcomes-A study in the Danish National Birth Cohort. PLoS One 2018 Sep;13(9):e0201842. https://doi.org/10.1371/ journal.pone.0201842.

16. Kaikkonen R, Härkänen T, Rahkonen O, Gould R, Koskinen $\mathrm{S}$. Explaining educational differences in sickness absence: a population-based follow-up study. Scand J Work Environ Health 2015 Jul;41(4):338-46. https://doi.org/10.5271/ sjweh.3499.

17. Niedhammer I, Lesuffleur T, Memmi S, Chastang JF. Working conditions in the explanation of occupational inequalities in sickness absence in the French SUMER study. Eur J Public Health 2017 Dec;27(6):1061-8. https:// doi.org/10.1093/eurpub/ckx052.

18. Sydsjö A, Claesson IM, Ekholm Selling K, Josefsson A, Brynhildsen J, Sydsjö G. Influence of obesity on the use of sickness absence and social benefits among pregnant working women. Public Health 2007 Sep;121(9):656-62. https://doi.org/10.1016/j.puhe.2006.11.010.

19. Diderichsen F, Evans T, Whitehead M. The Social Basis of Disparities in Health. In: Evans T, Whitehead M, Diderichsen F, Bhuiya A, Wirth M, editors. Challenging Inequities in Health. 1st ed. New York: Oxford University Press; 2001.

20. Jacobsen TN, Nohr EA, Frydenberg M. Selection by socioeconomic factors into the Danish National Birth Cohort. Eur J Epidemiol 2010 May;25(5):349-55. https:// doi.org/10.1007/s10654-010-9448-2.

21. Sydsjö G, Sydsjö A. Newly delivered women's evaluation of personal health status and attitudes towards sickness absence and social benefits. Acta Obstet Gynecol Scand 2002 Feb;81(2):104-11. https://doi.org/10.1034/j.16000412.2002.810203.x.

22. Melsom AM. Long-term sickness absence during pregnancy and the gender balance of workplaces. Scand J Public Health 2014 Nov;42(7):627-34. https://doi. org/10.1177/1403494814541596.
23. Danish Working Environment Authority. Gravides og ammendes arbejdsmiljø [The working environment of pregnant and breast feeding]. Copenhagen (DK): Danish Working Environment Authority, 2015 October. Report No.: At-vejledning A.1.8-5.

24. Danish Working Environment Authority. Gravides og ammendes arbejdsmiljø. [The working environment of pregnant and breast feeding]. Copenhagen (DK): Danish Working Environment Authority, 2002 February Report No.: At-vejledning A1.8.

25. Danish Working Environment Authority. Gravides og ammendes arbejdsmiljø [The working environment of pregnant and breast feeding]. Copenhagen (DK): Danish Working Environment Authority, 2009 January. Report No.: At-vejledning, A.1.8.

26. Danish Working Environment Authority. Gravides og ammendes arbejdsmiljø [The working environment of pregnant and breast feeding]. At-anvisning. Copenhagen (DK): Danish Working Environment Authority, 1998 Marts. Report No.: At-anvisning, Nr. 4.0.0.2.

27. Kristensen P, Nordhagen R, Wergeland E, Bjerkedal T. Job adjustment and absence from work in mid-pregnancy in the Norwegian Mother and Child Cohort Study (MoBa). Occup Environ Med 2008 Aug;65(8):560-6. https://doi. org/10.1136/oem.2007.035626.

28. Strand K, Wergeland E, Bjerkedal T. Job adjustment as a means to reduce sickness absence during pregnancy. Scand J Work Environ Health 1997 Oct;23(5):378-84. https://doi. org/10.5271/sjweh.235.

29. Jenssen IK, Berger MA. Pregnant at work [Gravid i jobb]. Ramazzini. 2017;24(4):9-12.

30. Ramlau-Hansen CH, Thulstrup AM, Nohr EA, Bonde JP, Sørensen TI, Olsen J. Subfecundity in overweight and obese couples. Hum Reprod 2007 Jun;22(6):1634-7. https://doi. org/10.1093/humrep/dem035.

Received for publication: 25 October 2018 